\title{
Dénes Nagy Architecture and Mathematics: From an Odd Couple to a New Partnership
}

Architecture and mathematics reunited? The Information Revolution also contributes to this process. Thus, the Third Industrial Revolution will not remain without an important development in the field of architecture:

- The Neolithic Agricultural Revolution contributed to the birth of the city. One may see in Catal Huyuk, Turkey an important stage of this process in situ nassendi.

- The Industrial Revolution contributed to the birth of mega-cities and, of course, to many social problems.

The Information Revolution may reverse some of the negative tendencies of the latter: the overcrowded industrial cities can be replaced by a better living environment where the "industrial work" is mostly performed by robots; where employees are not commuting to their offices, but working at computer terminals at home; and, last but not least, where the architects are benefitting from the use the of computer-aided architectural design (CAAD).

In the time of Euclid (3rd c. BC), architecture and mathematics became an odd couple. Vitruvius (1st c. AD) refers to various mathematicians, including Pythagoras and Thales, but not to Euclid. Similarly, Euclid does not discuss architecture-related geometrical problems, just "pure mathematics". The distance between architecture and mathematics became inevitable. Although in the last decades no student of architecture graduated without taking some mathematics-realated courses, the two fields kept their relative distances. They remained an odd couple. Some of the meeting points were partly eliminated. Nobody is interested in proportions...

The CAAD opens a new chapter. Partly the development of the related software, partly their use require more mathematics. I also believe that some of the "rejected" proportional theories may have a new renaissance. We may make experiments by comparing those "great old" (or "bad 
old") systems that some of the earlier generations of architects or mathematicians favoured. The reconstruction of buildings with CAAD also gives new challenges to historians of architecture. The data that day accumulated could be the input of some of the CAAD projects.

Will the work of the mathematicians and architects replaced by computers? Sure, the computer is quicker to sketch a design or calculate the integral of a function. Here the "winners" are given. BUT (all caps!) we still need those people who invent new algorithms and methodologies and those ones who use them creatively, as well as present new challenges. We should have a new partnership between mathematicians and architects, as well as, symmetrically, architects and mathematicians.

\section{The author.}

Denes Nagy is Hungarian mathematician and historian of science, living in Japan and Australia. He was educated in Hungary (Eotvos Lorand University). In 1986 he was invited to the U.S. as a Visiting Professor of Arizona State University (1986-1988). Later he worked as a Senior Lecturer of Mathematics at the University of the South Pacific (1989-1993). Since 2000 he is a Professor at the Australian Catholic University, St. Patrick's Campus, Fitzroy, Australia. He is the founding President of the International Society for the Interdisciplinary Study of Symmetry (ISISSymmetry), which has members in more than 50 countries. He is also the Co-Editor of the peer-reviewed scholarly journal Symmetry: Art and Science (1990- ). He has given invited talks in 17 countries in six languages. He has authored or edited 16 books and published more than 120 scholarly papers. 